\title{
Sexual Harassment Phenomena among Female Students at Mansoura University
}

\author{
Prof.Dr. Amani Shebl ${ }^{1}$, Dr.Hanan Awad M Elmashad ${ }^{2}$, Dr.Samia I Hassan ${ }^{2}$ \\ Medical Surgical Nursing ${ }^{1}$, Lecturer of Woman Health and Midwifery Nursing ${ }^{2}$, Faculty of Nursing, Mansoura \\ University, Egypt
}

\begin{abstract}
Background: Sexual harassment is considered to be a hot zone where the harassed still view it a taboo. This is due to community environment, norms, culture, and values. The present study aimed to explore sexual harassment phenomena among female students at Mansoura University.

Study design: An exploratory descriptive design was used in the conduction of the study.

The study setting: was carried out in different 17 faculties at Mansoura University, Egypt.

Study subjects: A total 1070 female students from various faculties were selected by convenient sample technique.

Tools of data collection: A structured interviewing questionnaire was designed by the researcher. It consisted of 2 parts; part one to assess general characteristics and second part consisted of questions related to exposure to sexual harassment, types, common places, response of the female and the recommended solution from the students' point of view etc.

Results: Showed that more than one third of female exposed to sexual harassment in the first semester of academic year either verbal harassment (100\%) or physical harassment (35.2\%). The public transportation was the most prominent place (84.5\%). Female student suffered from inability to study (58.6\%) and psychological effect as fear and anxiety (93.4\%). The students recommended solution to solve the problem as put strict laws for harassers (39.1\%), give interest to religious education in schools and universities (38.8\%) and wearing baggy clothes (35.6\%).
\end{abstract}

Conclusion: The sexual harassment was widespread problem among female that need community coordination with all sectors for eradicate it.

Keywords: sexual harassment, verbal harassment, physical harassment

\section{Introduction}

Violence against women can be described as a violation against human rights and a form of discrimination against females and shall mean all acts of gender-based violence that lead to physical, sexual, psychological and economic harm or suffering to women. It includes threats of which acts, coercion or arbitrary deprivation of liberty, whether occurring in public or even in private life (Bureau des Traités, 2016). Sexual violence is an undesirable and unwelcome behavior of a sexual nature that is upsetting to the individual and causes that individual to be threatened, humiliated or embarrassed (ILO, 2012a).

According to the $\boldsymbol{I L O}$ (2012a), harassment is any conduct towards someone depending on their age, disability, HIV status, domestic circumstances, sex, sexual orientation, gender reassignment, racial background, language, colour, religion, trade union affiliation or other opinion or belief, national or social origin, connection to a minority, property, birth or other status which is unreciprocated or undesirable and which influences the dignity of males and females at job. Di Martino and Musri, (2001) add to the concept of harassment that it is an unwanted conduct which could be verbal, non verbal, visual, psychological or physical.

The undesirable sexual attention of men is a common behavior around the world especially in employment and different stages of education especially for women and girls. The experience of sexual harassment phenomena (SHP) is worldwide transcending among all different levels of socioeconomic status and educational level and cutting across most national and cultural characteristics. It is one of the most endemic types of violence toward women and girls today. In spite of wide spread prohibition around the world, undesirable sexual attention is an unavoidable condition of work and education for important number of women and girls. The forms of behaviors that constitute it and the type and severity of harm that result from it vary by region, occupation, and discipline (Morgan and Gruber, 2011).

Sexual harassment phenomena is undesirable sexual advances, needs for sexual favors, and other verbal or physical behavior of sexual nature (Hassan et al., 2008). It is any unwanted sexual offensive or aggressive behavior that is carried out through any sexual physical or verbal act (Saguy, 2003). Also, it is considered as a damage of the recipient's dignity, as it creates an intimidating, hostile, humiliating, offensive environment for the recipient (Watson and Basics, 2006 \& Mohammed and Hashish, 2014). 
The phenomenon of sexual harassment has been a main concern in the entire world. In the US and the European countries the percentage of (SHP) cases was forty to sixty percent among women. Recently, the (SHP) has quickly increased in the Middle East's societies; particularly, the Egyptian society and it has become a very controversial issue as 62 percent of Egyptian men reported that they sexually harassed women (Ebaid, 2013).

Generally (SHP) is viewed as encompassing all kinds of disagreeable behavior of a sexual nature, whether verbal and/or physical. The types of (SH) have been comprehensively specified in the code of practice as verbal, unpleasant or suggestive comments, non-verbal or gestural as leering or ogling with suggestive overtones, visual as showing pornographic materials, Psychological as unwanted social invitations and Physical harassment as unacceptable touching (Nazari et al., 2007).

Understanding of personal, relationship, community and societal factors of sexual perpetrator can help identify several opportunities for prevention. The individual hazard variables incorporates alcohol and medication utilize, wrongdoing, empathic deficiencies, general forcefulness and acknowledgment of brutality, early sexual start, coercive sexual dreams, inclination for indifferent sex and sexual-chance taking, introduction to sexually unequivocal media, threatening vibe towards ladies, adherence to customary sex part standards, hyper-manliness, self-destructive conduct, and earlier sexual exploitation or execution $(\boldsymbol{C D C}, 2016)$.

Moreover relationship factors such as family environment described by physical violence and clash, previous history of physical, sexual, or emotional abuse, psychologically unaccommodating family environment, poor relationships between parent and their children, poor parent-kid connections especially with fathers, association with sexually aggressive. In addition poverty, decrease the employment chances, absence of institutional support from police and legal framework, general resilience of sexual viciousness inside the group, powerless group sanctions against sexual brutality culprits. Societal variables, for example, societal standards that bolster sexual brutality, male predominance and sexual privilege, powerless laws and arrangements identified with sexual viciousness $(C D C, 2016)$.

There are many consequences of sexual harassment to both the organization and the individual. Firstly on organization there are high job turnover, uncontrolled non-attendance, low self-esteem as well as decrease productivity and increase the need for therapeutic cases. Besides, women suffered lower levels job satisfaction than others. They have a tendency to be absent from work using sick leaves an apology. Secondly consequence on the individual emotional distress maybe showed in side effects including irritability, depression, anxiety, anger and sleeplessness. All these could influence inspiration and adequacy at work and family relations at home (Fitzgerald et al., 1997 and Dansky \& Kilpatrick, 1997, Nazari et al., 2007, Merkin and Shah, 2014).

\section{Significance of the study}

Sexual harassment is a serious and universal societal problem. In Egypt there is increasing in number of sexual harassment cases so ECWR described it as social cancer. There are various components and reasons for inappropriate behavior on ladies in Egypt as sexual harassment; some of them are related to Egyptian economic status which leads to poverty, unemployment and social mistreatment as in marriage conditions in Egypt (El Deep, 2013).

According to the survey released by the United Nations Entity for Gender Equality (UNEGE) and the Empowerment of Women on sexual harassment, majority of Egyptian women were exposed to sexual harassment in one way or the other $(99.3 \%), 96.5 \%$ experienced physical harassment, and $95.5 \%$ experienced sexual harassment through verbally abusive language (El Deep, 2013). In addition, (Fahmy et al., 2014) reported that $100 \%$ of the studied female in Helwan and Subra Elkheima followed by $98 \%$ in Masr Elqadema had been exposed to sexual harassment. Sexual harassment in Egypt has been an emergent social threat. So this study was conducted to explore sexual harassment phenomena among female students at Mansoura University.

\section{Aim of the study}

This study aimed to explore sexual harassment phenomena among female students at Mansoura University.

\section{Research questions:}

1. What is the prevalence of sexual harassment among the study sample?

2. What are the types and effect of sexual harassment among the study sample?

3. What are the female students' suggestions to solve sexual harassment phenomenon?

\section{Operational definition}

1. Harassment is any behavior that demeans, humiliates, embarrasses, disturbs, insults or discomforts an individual, in whatever manner, by words, gestures, swearing or insults.

2. Physical harassment:

- Inappropriate touching of a person's body or clothing.

3. Verbal harassment:

- Commenting about a person's uniform, individual behavior, individual (romantic) relationships, or body.

- Making sexual or sex-based jokes or innuendoes. 
- $\quad$ Requesting sexual supports or dates; spreading rumors about a person's personal or sexual life.

Study design: Across section design was used.

Study setting: This study was carried out at different faculties in Mansoura University from the period of February 2015 to June 2015

Study subjects: A total number equal 1070 female students from various faculties were selected by convenient sample technique .Female students ranged from 40- 70 student from each faculty.

Sample size:

This aim of the study is to estimate the prevalence of harassment among the students of the Mansoura University. A previous study showed that prevalence of physical harassment 78.2\% (Mamaru et al., 2015). To calculate the sample size with precision/absolute error of 5\% and type 1 error of 5\%:

\section{Sample size:}

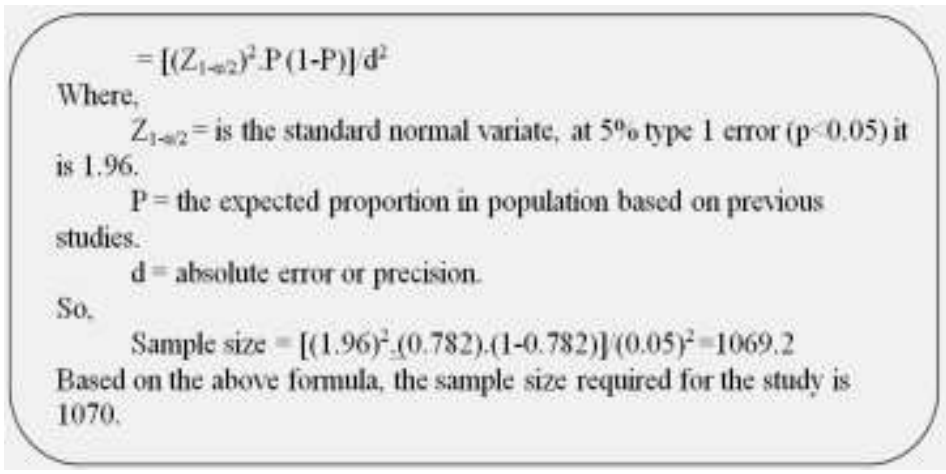

\section{Tool for data collection}

The tool used for data collection was structured interviewing questionnaire developed by the researchers after reviewing the relevant literature. It consisted of two parts:

Part I: It included general characteristics of the study sample e.g. age, residence, and marital condition.

Part П: It was consisted of questions related to exposure to sexual harassment, types, common places, response of the female and the recommended solution from the students' point of view etc.

Validity of the tool

The tool tested for the content validity by five experts in the field.

\section{Reliability of the tool}

The result of cronbachs alpha was 0.803 suggesting that items of questionnaire were highly correlated.

Field work

- Data collection was carried out from February to June 2015 from predetermined settings at free time of students between their lectures for three days / week.

- The researchers introduced themselves to each student, a full explanation about the aim and the scope of the study was given to obtain female students consent.

- The researcher distributed the prepared tool for each student and the time required for complete the tool was $10-15$ minutes.

- The data was collected from each faculty until reach to the predetermined sample size.

\section{Statistical analysis}

The statistical analysis of data was done by using SPSS program (statistical package for social science) version 16. The data was tabulated and presented as frequency and proportion for qualitative data.

\section{Ethical considerations}

The aim of the study was explained to each student before starting the study to gain their confidence and trust. Oral consent was obtained from each student to participate in the study, after ensuring that data collected will be treated confidentially. All ethical considerations were clarified to each student before explaining the nature of the study.

\section{Results}

Table (1): Frequency distribution of studied sample according to general characteristics

\begin{tabular}{|l|c|c|}
\hline \multicolumn{1}{|c|}{ Items } & NO. $(\mathbf{n = 1 0 7 0})$ & \% \\
\hline Age & & \\
Less than 20 & $\mathbf{3 6 2}$ & $\mathbf{3 3 . 8}$ \\
$20-25$ & $\mathbf{6 9 2}$ & $\mathbf{6 4 . 7}$ \\
More than 25 & $\mathbf{1 6}$ & $\mathbf{1 . 5}$ \\
\hline
\end{tabular}




\begin{tabular}{|l|c|c|}
\hline Residence & $\mathbf{7 0 9}$ & \\
Rural & $\mathbf{3 6 1}$ & $\mathbf{6 6 . 3}$ \\
Urban & & 33.7 \\
\hline Marital status & $\mathbf{1 9 2}$ & $\mathbf{1 7 . 9}$ \\
Married & $\mathbf{8 7 8}$ & $\mathbf{8 2 . 1}$ \\
Not married & $\mathbf{7 9}$ & $\mathbf{7 . 4}$ \\
\hline Working & $\mathbf{9 9 1}$ & $\mathbf{9 2 . 6}$ \\
Not working & \\
\hline
\end{tabular}

Table (1) shows that the higher percentage of the studied sample age was ranged from 20-25 years old $(64.7 \%)$ and $66.3 \%$ of them resident in rural areas. The majorities of them were not working $(92.6 \%)$ and not married $(82.1 \%)$.

Table (2): Frequency distribution of studied sample according to prevalence and types of sexual harassment in

\begin{tabular}{|l|c|c|}
\multicolumn{2}{|c|}{ previous year } \\
\hline Items & NO. $(\mathbf{n = 1 0 7 0})$ & $\%$ \\
\hline Prevalence & & \\
Exposed & $\mathbf{9 6 8}$ & $\mathbf{9 0 . 5}$ \\
Not exposed & $\mathbf{1 0 2}$ & $\mathbf{9 . 5}$ \\
\hline Types of sexual harassment. & & \\
Verbal harassment & $\mathbf{9 4 8}$ & $\mathbf{8 8 . 6}$ \\
Physical harassment & $\mathbf{9 3 4}$ & $\mathbf{8 7 . 3}$ \\
\hline
\end{tabular}

Table (2) illustrates that the majority of studied sample exposed to verbal harassment and physical harassment in previous year which constituted $(88.6 \%, 87.3 \%$ respectively).

Table (3): Frequency distribution of studied sample according to prevalence and the most common places of sexual harassment in first semester of academic year

\begin{tabular}{|l|c|c|}
\hline \multicolumn{1}{|c|}{ Variables } & NO. $(\mathbf{n}=\mathbf{1 0 7 0})$ & $\%$ \\
\hline prevalence & & \\
Exposed & $\mathbf{4 2 6}$ & $\mathbf{3 9 . 8}$ \\
Not exposed & $\mathbf{6 4 4}$ & $\mathbf{6 0 . 2}$ \\
\hline Places of harassment(n=426) & & \\
\hline Public transportation & $\mathbf{3 6 0}$ & $\mathbf{8 4 . 5}$ \\
\hline The street & $\mathbf{1 5 8}$ & $\mathbf{3 7 . 1}$ \\
\hline The university & $\mathbf{6 0}$ & $\mathbf{1 4 . 1}$ \\
\hline Cellular phones & $\mathbf{3 7 5}$ & $\mathbf{8 8 . 1}$ \\
\hline Home & $\mathbf{6}$ & $\mathbf{1 . 4}$ \\
\hline
\end{tabular}

Multiple responses allowed

It was clear that more than third of the studied sample exposed to sexual harassment in the first semester of academic year $(39.8 \%)$. The most common places of harassment were the public transportation followed by the street $(84.5 \%, 37.1 \%$ respectively).

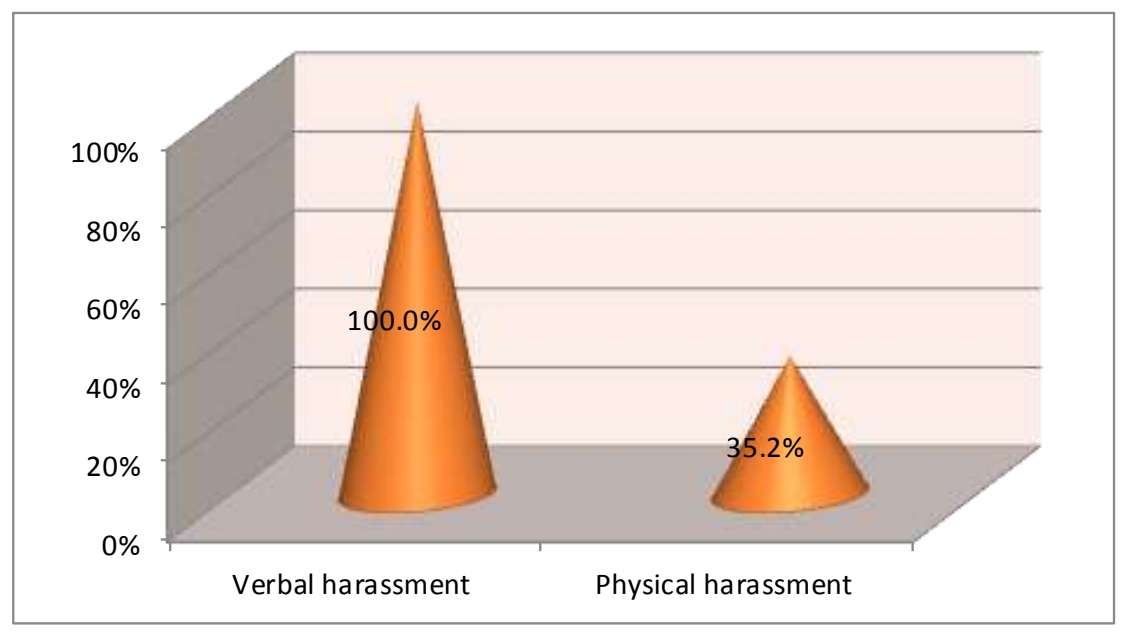

Figure (1): Shows distribution of studied sample according to types of sexual harassment 
Table (4): Frequency distribution of studied sample according to the reasons of sexual harassment from female point of view

\begin{tabular}{|l|c|c|}
\hline \multicolumn{1}{|c|}{ Items } & NO.(n=1070) & \% \\
\hline Media and porn movies & 860 & 80.4 \\
\hline Spread of the internet and face book & 620 & 57.9 \\
\hline Parental control weakness & 565 & 52.8 \\
\hline The absence of legal deterrence & 487 & 45.5 \\
\hline Crowdness in public transportation & 453 & 42.3 \\
\hline Family disintegration & 432 & 40.4 \\
\hline psychological and medical condition & 392 & 36.6 \\
\hline Mixing between boys and girls & 371 & 34.7 \\
\hline Fondling the couple in front of the children & 347 & 32.4 \\
\hline Loss of safety & 306 & 28.6 \\
\hline Deteriorating of economic conditions & 291 & 27.2 \\
\hline Absence of responsibility & 280 & 26.2 \\
\hline The school queues & 129 & 12.1 \\
\hline
\end{tabular}

Table (4) shows that the most prominent reasons of sexual harassment behavior among youth from female point of view were media and porn movies followed by spread of the internet and face book $(80.4 \%$, $57.9 \%$ respectively). Around half of them stated that parental control weakness, the absence of legal deterrence and crowded in public transportation were other reasons $(52.8 \%, 45.5 \%, 42.3 \%$ respectively).

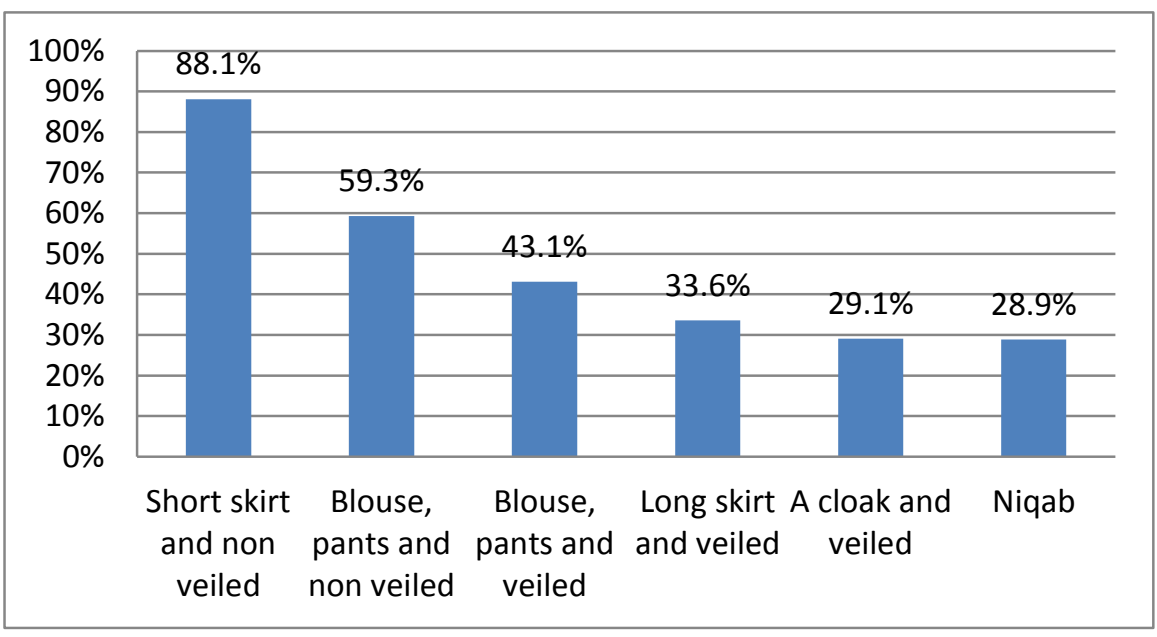

Figure (2): Shows distribution of studied sample according to exposure to sexual harassment based on appearance

Based on students' points of view, the most liable women for exposure to sexual harassment wore short skirt and non veiled $(88.1 \%)$ followed by who wore blouse, pants and non veiled $(59.3 \%)$. While the women who wore niqab and a cloak and veiled constituted $(28.9 \%, 29.1 \%)$ respectively (figure 2$)$.

Table (5): Frequency distribution of female responses when exposed to harassment

\begin{tabular}{|l|c|c|}
\hline \multicolumn{1}{|c|}{ Items } & NO. (n=426) & $\%$ \\
\hline Expression of anger and distress by using facial expressions & $\mathbf{4 2 6}$ & $\mathbf{1 0 0}$ \\
\hline Ignore the situation for fear of repercussions & $\mathbf{3 6 5}$ & $\mathbf{8 5 . 9}$ \\
\hline Escape from the place & $\mathbf{2 7 7}$ & $\mathbf{6 5 . 0 2}$ \\
\hline Request for help from others (university guards or one close) & $\mathbf{2 1 8}$ & $\mathbf{5 1 . 2}$ \\
\hline Using any tool & $\mathbf{2 1 2}$ & $\mathbf{4 9 . 8}$ \\
\hline Confusion and loss of the ability to act & $\mathbf{1 9 3}$ & $\mathbf{4 5 . 3}$ \\
\hline Verbal censure and reprimand & $\mathbf{1 6 8}$ & $\mathbf{3 9 . 4}$ \\
\hline
\end{tabular}

Table (5) illustrates that there were different responses from female when exposed to harassment. The study sample responses were expression of anger and distress by using facial expressions, ignore the situation for fear of repercussions followed by escape from the place $(100 \%, 85.9 \%, 65.02 \%$ respectively). The responses around half of them were request for help from others, backlash using any tool and confusion and loss of the ability to act $(51.2 \%, 49.8 \%, 45.3 \%$ respectively). 
Table (6): Frequency distribution of studied sample according to effect of sexual harassment on female

\begin{tabular}{|l|c|c|}
\hline \multicolumn{1}{|c|}{ Items } & No(n=426) & \% \\
\hline 1.The physical effect: & $\mathbf{1 0 0}$ & \\
Headache & $\mathbf{3 0 5}$ & $\mathbf{2 3 . 5}$ \\
Difficult in sleeping & $\mathbf{8 0}$ & $\mathbf{1 8 . 8}$ \\
Mores & & \\
\hline 2.Psychological effect: & $\mathbf{4 0 0}$ & $\mathbf{9 3 . 4}$ \\
Fear and anxiety & $\mathbf{3 0 7}$ & $\mathbf{7 2 . 1}$ \\
Anger & $\mathbf{5 0}$ & $\mathbf{1 1 . 7}$ \\
Depression & $\mathbf{2 5 0}$ & $\mathbf{5 8 . 6}$ \\
Inability to study & & \\
3.Social effect: & $\mathbf{5 0}$ & $\mathbf{1 1 . 7}$ \\
Loneliness & $\mathbf{4 2 6}$ & $\mathbf{1 0 0}$ \\
Indignant feeling toward the opposite sex & \multicolumn{2}{|c}{} \\
\hline
\end{tabular}

Table (6) shows that the prominent physical effects of sexual harassment were difficult in sleeping and headache $(71.6 \%, 23.5 \%$ respectively). While psychological effects were fear and anxiety and anger $(93.4 \%$, $72.1 \%$ respectively). The social effect was indignant feeling toward the opposite sex $(100 \%)$.

Table (7): Frequency distribution of studied sample according to the behaviors that suggest the idea of sexual harassment

\begin{tabular}{|l|c|c|}
\hline \multicolumn{1}{|c|}{ Items } & NO.(n=1070) & \% \\
\hline Insist on connecting the female to home or work, despite repeated rejection & $\mathbf{1 5 4}$ & $\mathbf{1 4 . 4}$ \\
\hline Insist on female invitation to drink or picnics despite repeated rejection & $\mathbf{1 3 4}$ & $\mathbf{1 2 . 5}$ \\
\hline Sexual jokes or stories that carry more than one meaning & $\mathbf{4 0 1}$ & $\mathbf{3 7 . 5}$ \\
\hline Sexual image or sexual comments, which carry more than one meaning & $\mathbf{4 4 1}$ & $\mathbf{4 1 . 2}$ \\
\hline Telephone harassment & $\mathbf{3 7 7}$ & $\mathbf{3 5 . 2}$ \\
\hline Stalking / Tracking & $\mathbf{3 3 5}$ & $\mathbf{3 1 . 3}$ \\
\hline Verbal flirting or whistle & $\mathbf{4 1 3}$ & $\mathbf{3 8 . 6}$ \\
\hline The man revealed to some members of his body or the hint & $\mathbf{4 4 4}$ & $\mathbf{4 1 . 5}$ \\
\hline Bad outlook for the woman's body & $\mathbf{7 6 1}$ & $\mathbf{7 1 . 1}$ \\
\hline Sexual verbal meaning & $\mathbf{6 0 9}$ & $\mathbf{5 6 . 9}$ \\
\hline
\end{tabular}

Table (7) shows the behaviors that suggest the idea of sexual harassment among female students. The most common behaviors were bad outlook for the woman's body $(71.1 \%)$ followed by sexual verbal meaning $(56.9 \%)$, the man revealed to some members of his body (41.5\%), sexual image or sexual comments, which carried more than one meaning $(41.1 \%)$, whistle and verbal flirting $(38.6 \%)$ and sexual jokes or stories that carry more than one meaning $(37.5 \%)$.

Table (8): Females suggestions to eliminate sexual harassment

\begin{tabular}{|l|c|c|}
\hline \multicolumn{1}{|c|}{ Items } & No.(n=1070) & \% \\
\hline Put strict laws for Harassers & $\mathbf{4 1 8}$ & $\mathbf{3 9 . 1}$ \\
\hline $\begin{array}{l}\text { Give interest to religious education in schools and universities and the work of a religious } \\
\text { seminars and awareness campaigns. }\end{array}$ & $\mathbf{4 1 5}$ & $\mathbf{3 8 . 8}$ \\
\hline Wearing baggy clothes. & $\mathbf{3 8 1}$ & $\mathbf{3 5 . 6}$ \\
\hline Put legal control over the media and stop porn channels for broadcasting. & $\mathbf{2 0 4}$ & $\mathbf{1 9 . 1}$ \\
\hline Lack of congestion and mixing in transportation. & $\mathbf{1 7 9}$ & $\mathbf{1 6 . 7}$ \\
\hline Raising awareness regarding values and good morals. & $\mathbf{1 7 8}$ & $\mathbf{1 6 . 6}$ \\
\hline Parents accompany their children and make them aware of the existence of control as family & $\mathbf{1 7 3}$ & $\mathbf{1 2 . 8}$ \\
\hline Increasing security in the streets and increase the university guards. & $\mathbf{1 5 8}$ & $\mathbf{1 4 . 8}$ \\
\hline Put punishment for harassers in a public square in front of all & $\mathbf{1 4 9}$ & $\mathbf{1 3 . 9}$ \\
\hline Lack of mixing between boys and girls. & $\mathbf{1 4 7}$ & $\mathbf{1 3 . 7}$ \\
\hline The proper education of children. & $\mathbf{1 2 3}$ & $\mathbf{1 1 . 5}$ \\
\hline Improving economic conditions. & $\mathbf{8 7}$ & $\mathbf{8 . 1}$ \\
\hline Put censorship on internet. & $\mathbf{8 3}$ & $\mathbf{7 . 8}$ \\
\hline Not to use cosmetics & $\mathbf{4 8}$ & $\mathbf{4 . 4}$ \\
\hline Lack of fondling pair wife in front of the children. & $\mathbf{2 2}$ & $\mathbf{2 . 1}$ \\
\hline Stop girls from going out until late & $\mathbf{1 5}$ & $\mathbf{1 . 5}$ \\
\hline Preventing drugs that stimulate desire and absent consciousness & $\mathbf{5}$ & $\mathbf{0 . 5}$ \\
\hline
\end{tabular}

Table (8) shows that the suggestions to eliminate sexual harassment among more than one third of female students were put strict laws for harassers, give interest to religious education in schools and universities and wearing baggy clothes $(39.1 \%, 38.8 \%, 35.6 \%$ respectively $)$.And around one quarter of them suggested legal control over the media for example stop porn channels for broadcasting, lack of congestion and mixing in transportation and raising awareness regarding values and good morals (19.1\%,16.7\%,16.6\% respectively). 


\section{Discussion}

The aim of the present study was to explore sexual harassment phenomena among female student at Mansoura University. This aim was significantly achieved through answered the research questions. The main study findings reported that during the first semester of academic year 2015 more than one third of female exposed to harassment and all of them exposed to verbal harassment, plus more than one third exposed to physical harassment. The reasons of sexual harassment behavior among youth from females' points of view were a lack of control on media and porn movies, spread of the internet and face book, parental control weakness, the absence of legal deterrence and crowded in public transportation. The students' suggestions to control this phenomenon were put strict laws for harassers, give interest to religious education in schools and universities, wearing baggy clothes and facilitating the means of transportation.

Regarding to prevalence of sexual harassment, more than one third of the studied students exposed to harassment. the current study findings were in contrast with Hassan et al., (2008) study about clouds in Egypt's sky" sexual harassment: from verbal harassment to rape who reported that (83.3\%) of Egyptian women reported exposed to harassment. Also, the current study findings were in contrast with Hejase, (2015) study in Lebanon about sexual harassment in the workplace who reported that $16 \%$ of the female respondents had experienced sexual harassment. Also, the study results disagreement with Shattla et al., (2012) study about psychological impact of sexual harassment among Menofia university student, Egypt who revealed that $80.1 \%$ of students had been exposed to sexual harassment.

Concerning to types of sexual harassment among the harassed females, all of them exposed to verbal harassment plus more than one third exposed to physical harassment. The present study results were consistence with Truluck, (2015) study results about understanding street harassment in Jordan who found that majority of women exposed to verbal harassment $(88.9 \%)$ followed by physical harassment $(22.2 \%)$. This may be due to female in Egyptian society may be blamed if they reported physical sexual harassment. This study result was consistent with study conducted by Elbasuony et al., (2016) at Dakahlia, Egypt who reported that the popular kind of sexual violence was verbal harassment.

Regarding to places of harassment, the common places of harassment were multiples but the majority of students exposed to harassment at the public transportation followed by the streets which constituted more than one third. The present study results were consistence with Hassan et al., (2008) who reported that $91.5 \%$ of Egyptian women and $96.3 \%$ of foreign women faced sexual harassment on public transportation. While the current study findings were in contrast with Hollaback, (2012) study about Croatia street harassment survey who found that $99 \%$ of women had experienced street harassment. Also, the current study results disagreement with Fahmy et al., (2014) study about sexual harassment in greater Cairo: effectiveness of crowd sourced data who reported that $(81.4 \%)$ of women were exposed to harassment on street followed by on public transportation $(14.8 \%)$.

In addition, the present study results revealed that majority of female exposed to harassment through cellular phone. In the same line Duggan, (2014) reported that harassment not stop on street, work, campus and general places it involved online, as one quarter of young women experienced sexual harassment while online. This may be due to harassers protect themselves from female responses and wanted to become unknown one.

Concerning to the reasons of sexual harassment behavior among youth from female point of view, it was multiple. The most prominent reasons were lack of control on media and porn movies followed by spread of the internet and face book, parental control weakness, the absence of legal deterrence and crowded in public transportation. The current study results were in agreement with Fahmy et al., (2014) study who reported that reasons for the presence of sexual harassment were lack of religious consciousness followed by a lack of supervsion on the internet and media.

While the current study findings were in disagreement with $\boldsymbol{E l}$ Deep, (2013) study about ways and methods to eliminate sexual harassment in Egypt who reported that majority of male was attributing harassment to a woman's wearing tight clothes, putting make-up in a provocative way, non-compliance with conventional customs and traditions, girls walk and girls talk. This contradicting due to difference in male point of view as harasser than female as victims.

Concerning to women exposure to sexual harassment based on appearance, the present study results revealed that from students' points of view all women exposed to harassment regardless their clothes and higher percentage of them wore short skirt and non veiled and the lower percentage wore niqab or a cloak and veiled. The current study results were in agreement with Hollaback, (2013) sexual harassment stories who stated that street harassment, like sexual assault and rape, was not caused by a woman's provocative clothing or behavior and victims reported being harassed while wearing all types of clothing either revealing or conservative.

Moreover, the present study results was in same line with Fahmy et al., (2014) study results who revealed that more than half of woman reported that females who wore narrow clothing and non veiled was the most susceptible to harassment $(61 \%)$, followed by a woman who wore clothing, a woman who wore a black cloak $(50.9 \%)$, a woman who wore a skirt and a tunic $(51.7 \%)$ and finally with the woman wore the niqab, to be 
the least likely to get harassed. Also, in the same line Hollaback, (2013) stated that ladies wearing the hejap were the most susceptible to harassment more than unveiled ladies and to the extent that even those who fully cover up.

Regarding to effect of sexual harassment, the current study highlighted that the majority of students complained from fear and anxiety, more than two third complained from difficult sleeping and anger followed by inability to study and headache. The present study findings were in agreement with Buchanan \& Fitzgerald, (2008) and Buchanan, et al., (2009) who stated that sexual harassment had been associated with multiple painful psychological symptoms, such as post traumatic stress, depression, physical health problems, and work or academic disengagement in both men and women. The present study findings were in same line with Alazab, (2011) study about workplace harassment associated health hazards and quality of work life among harassed workers who found that more than half of harassed woman had insomnia, lack of concentration and headache. Moreover, similarity with present study Dhlomo, et al., (2015) reported that sexual harassment negatively impacts the academic performance of the female students.

The present study findings revealed that there were different responses from female when exposed to harassment and the response of every female to sexual harassment was multiple. The data highlighted that the responses among the majority of the university students who exposed to harassment were expression of anger and distress by using facial expressions and ignorance of the situation for fear of repercussions followed by escape from the place and request for help from others among more than half of students, while less than half used any tool as defense mechanism. This is may be due to the nature of the Egyptian culture as female feeling of shame and fear from the society view. Also, in western society blaming from others belongs to female rather than male. The current study findings were similar with British Crown, (2015) study about sexual harassment report as the most common action taken to stop sexual behavior among British woman was ignorance of behavior and avoided the person.

Regarding to the suggestions to eliminate sexual harassment from opinions of female students in Mansoura university, the current study findings revealed that there were many ways and methods to eliminate sexual harassment as put strict laws for harassers, religious education in schools and universities, wearing baggy clothes, as reported by more than one third of the study sample while less than quarter agreed with put legal control over the media (for example stop porn channels for broadcasting) and lack of congestion in transportation. Similarity, El Deep, (2013) reported that the majority of strangers' female and some of the Egyptian female and men suggested that there was have to implement existing laws to deal with sexual harassment, and put special legislation criminalizing linked to sexual harassment. In addition, create efficient security system and put censorship for the media.

\section{Conclusion}

The present study highlighted that sexual harassment was common among female students as the majority of them exposed to it in their previous year and more than one third exposed to it at time of the study. The verbal harassment was more common than physical harassment and the most common places were the public transportation and the streets. All women were exposed to harassment regardless their clothes but the higher percentage among those who wore short skirt and non veiled. The students' responses were expression of anger or ignorance of the situation or escape from the place. Moreover, the reasons of sexual harassment behavior among youth from female point of view were a lack of control on media and porn movies followed by spread of the internet and face book, parental control weakness, the absence of legal deterrence and crowded in public transportation. So the female students in Mansoura University Egypt recommended ways to control this problem as put strict laws for harassers, give interest to religious education in schools and universities, wearing baggy clothes, and facilitating of transportation.

\section{The present study recommended the following:}

\section{Recommendation}

- Raising religious awareness related to sexual societal problems.

- Awareness raising program for youth either man or woman to eliminate sexual harassment and discuss the difference between normal relations and those that violate others.

- Raising awareness to break the female silence to take appropriate action towards harassment.

- Further study on large sample and handle this phenomena from different categories of the community.

Limitation of the study

Most of students in the present study accepted to participate in the study and completed the questionnaire without writing their names due to shame and sensitivity of the matter.

\section{Acknowledgments}

The authors are gratified to whole participants' students in this study. Finally gratifying merit for all person who help in publishing this article. 


\section{References}

[1]. Alazab, R. M.(2011):Workplace Harassment Associated Health Hazards And Quality Of Work Life Among Harassed Workers In An International Corporation ,Egyptian Journal of Occupational Medicine, 2011; 35 (2) : 211-226

[2]. British Crown (2015): Sexual Harassment Report. Available at: https://www.gov.uk/government/publications/british-army-sexualharassment-report-2015.

[3]. Buchanan, N. T., Bergman, M. E., Bruce, T. A., Woods, K. C., \& Lichty, L. L. (2009): Unique and joint effects of sexual and racial harassment on college students'well-being. Basic and Applied Social Psychology, 31, $267-285$.

[4]. Buchanan, N. T., \& Fitzgerald, L. F. (2008): Effects of racial and sexual harassment on work and the psychological well-being of African American women. Journal of Occupational Health Psychology, 13, 137-151.

[5]. Bureau des Traités (2016): "Liste complète". Conventions.coe.int. Retrieved 2016-04-03. Available at: https://en.wikipedia.org/wiki/Violence_against_women.

[6]. Centers for Disease Control and Prevention (CDC). (2016): Sexual Violence: Risk and Protective Factors. Available at http://www.cdc.gov/violenceprevention/sexualviolence/riskprotectivefactors.html.

[7]. Dansky, B. and Kilpatrick, D. (1997): Effects of Sexual Harassment', in W. 0'Donohue (ed') Sexual Harassment: Theory, Research, and Treatnent 'Needham Heights, N4A: Allyn \& Bacon, pp.152-174

[8]. Dhlomo, T., Muchena, P. and Gunhu, M.R. (2015): Sexual Harassment Symptoms: The Effect on Female College Students' Academic Functioning. IOSR Journal Of Humanities And Social Science (IOSR-JHSS), Volume 20, Issue 8, Ver. I, PP 40-43.

[9]. Di Martino, V. and Musri, M. (2001): Guidance for the Prevention of Stress and Violence at the Workplace. Kuala Lumpur, Departmetn of Occupational Safety and Health Malaysia.

[10]. Duggan M. (2014): PEW Research Center. "Online Harassment". Available at "http://www.pewinternet.org/2014/10/22/onlineharassment/".

[11]. Ebaid, N.(2013): Sexual Harassment in Egypt: A Neglected Crime An assessment for the Egyptian Government performance in regard to the Sexual Harassment in Egypt.

[12]. Elbasuony, R.A.A., El-Sayed, H.E.M. and El-Nemer, A.M.R. (2016): Prevalence, Pattern and Risk Factors of female sexual violence, IOSR Journal of Nursing and Health Science (IOSR-JNHS) e-ISSN: 2320-1959.p- ISSN: 2320-1940 Volume 5, Issue 6 Ver. VII, PP 79-88.

[13]. El-Deeb, B. (2013): 'Study on Ways and Methods to Eliminate Sexual Harassment in Egypt', available at (http://harassmap. org/en/wp-content/uploads/2016/02/287_Summaryreport_eng_low-1.pdf)

[14]. Fahmy,A, Abdelmonem,A., Hamdy,E. Badr,A. et al ( 2014):Sexual Harassment in Greater Cairo: Effectiveness of Crowd sourced Data. International development research center Available at www.harassmap.org

[15]. Fitzgerald, 1.F., Swan, S. and Magley, V,J. (1997): Butwas it Really Sexual Harassment? Legal, Behavìoral, and Psychological Definitions of the Workplace Victimization of Women', in W. 0'Donohue (ed.),Sexual Harassnent: fheory, Research, and Lreat 'ment Needham Heights, MA: Allyn \& Bacon,pp. s-28.

[16]. Hassan, R.M., Shoukry, A. and Abul Komsan, N.( 2008): Study About Clouds In Egypt's Sky" Sexual Harassment: From Verbal Harassment To Rape. Available at Website: www.ecwronline.org

[17]. Hejase, H. J., (2015): Sexual Harassment in the Workplace: An Exploratory Study from Lebanon, Journal of Management Research Vol. 7,No. 1 pp107-121

[18]. Hollaback (2012): Croatia, Croatia Street Harassment Survey 2012, available at: http://www.ihollaback.org/wp-content/uploads/ 2012/06/Hollaback-Croatia_Online-street-harassment-survey.pdf

[19]. Hollaback (2013): Read \& Share Stories, Available at: http://www.ihollaback.org/share/.

[20]. ILO (2012a): SOLVE: Integrating Health Promotion into Workplace OSH Policies. Geneva, 2nd edition by the International Labour Office.

[21]. Mamaru,A., Getachew, K. , and Mohammed, Y ( 2015 ): Prevalence of Physical, Verbal and Nonverbal Sexual Harassments and Their Association with Psychological Distress among Jimma University Female Students: A Cross-Sectional Study, Ethiop J Health Sci. 25(1): 29-38.

[22]. Merkin, R.S. and Shah, M. K.(2014): The impact of sexual harassment on job satisfaction, turnover intentions, and absenteeism: findings from Pakistan compared to the United States, Springerplus. 3: 215.

[23]. Mohammed, G.F. and Hashish, R.K.(2014): Sexual violence against females and its impact on their sexual function Egyptian Journal of Forensic Sciences Volume 5, Issue 3, September 2015, Pages 96-102.

[24]. Morgan, P., and Gruber, J. E. (2011): Violence against Women at Work and in Schools, Claire M. R. Jefferey.L.E., and Raquel. K. B., (Eds.), Sourcebook on Violence Against Women, Second Edition, pp. 75-94, Sage Publications Inc.

[25]. Nazari, M.I., Kum, L.C. and Foong, C.B. (2007): Factors Influencing Sexual Harassment In The Malaysian Workplace, Asian Academy of Management Journal, Vol. 12, No. 2, 15-31.

[26]. Saguy, A.C.(2003): What Is Sexual Harassment? From Capitol Hill to the Sorbonne. N.p.: University of California.

[27]. Shattla,S.,E., Abd Elrahman A.F., \&Abd.G.A (2012): psychological impact of sexual harassment among Menofia university student, Egypt available at http://www.eulc.edu. eg/eulc_v5/Libraries/ Thesis/Browse ThesisPages.aspx?fn= PublicDraw Thesis\& BibID $=11449814$

[28]. Truluck, E. (2015): Understanding Street Harassment in Jordan: A Comparative Analysis of Syrian Refugees' and Jordanian Citizens' Experiences of Street Harassment in Jordanian Host Communities. Available at: http://digitalcollections. sit. edu/isp_ collection/2056

[29]. Watson, J. (2006): Basics In: Sexual harassment: Managers' questions answered Equal Opportunities Commission; 2006:2-4. 